\title{
COLOR AND GLOSS EVALUATION IN DECORATIVE STAIN APPLIED TO CASES OF Pinus radiata WOOD TREATED WITH COPPER AZOLE MICRONIZED TYPE C
}

\author{
R. Garay ${ }^{1, \star}$, M. Inostroza ${ }^{2}, A$. Ducaud $^{3}$
}

\begin{abstract}
Six treatments (one control and five decoration coatings) were applied to radiata pine wood treated with micronized copper azole for outdoor use at a rate of $3,08 \mathrm{~kg} / \mathrm{m}^{3}$ retention. One decoration coating was applied prior to impregnation, prestain and two decoration coatings were applied in a mixture with the micronized copper azole preservative Black Cylinder and Red Cylinder. The following two varnishes were tested: a water-based varnish and a solvent-based varnish. Additionally, untreated radiata pine specimens were tested as a reference. The changes in the gloss and color of these five decorative coatings were evaluated after undergoing natural aging tests for three months and accelerated aging trials during exposure to ultra-violet radiation of $340 \mathrm{~nm}$ for 500 hours. In the accelerated aging trials treatments, changes in gloss and color showed the lowest variations in treatment trials prestain and Black Cylinder and the highest variations in treatment trial Red Cylinder. In the aging tests trials, changes in gloss and color showed the lowest variations in treatment trials prestain and Black Cylinder. The costs of each decorative coating were assessed in terms of performance according to timber volume coated. The lowest cost of the three decoration treatments was prestain, with a value of $16 \mathrm{US} \$ / \mathrm{m}^{3}$, followed by Black Cylinder with a value of 24 $\mathrm{US} \$ \mathrm{~m}^{3}$. Compared with the alternative siding products available in the market, such as fiber cement and vinyl siding, colored wood treated with prestain is competitive with vinyl siding, with $58 \%$ lower costs than fiber-cement.
\end{abstract}

Keywords: CIELAB coordinates, radiata pine, wood decorative coating, wood preservatives, wood impregnated.

\section{INTRODUCTION}

The global trend regarding wood preservatives based on copper oxides, chromium and arsenic (CCA) is to gradually replace these materials with more sustainable products. In Chile, lesser environmentally impacting preservatives have been introduced in recent years, such as copper azole preservative (CAB) and micronized copper azole, type C ( $\mu$ CA-C), which deliver increased effectiveness at lower retention rates, resulting in lower costs and easier penetration. Moreover, such products can be used under the same conditions as CCA-treated wood, with the exception of marine applications (NCH 819 2012).

\footnotetext{
${ }^{1}$ University of Chile, Forest Science Faculty, Department Wood Engineering, Santiago, Chile.

${ }^{2}$ Private Consultant. Santiago, Chile.

${ }^{3}$ Technical manager ArchQuimetal, Santiago, Chile.

•Corresponding autor: rgaray@uchile.cl

Received: 04.06.2015 Accepted: 03.10.2016
} 
However, the area of wood protective coatings has significantly improved in terms of efficiency and sustainability. The current trend is to use porous and water-based products, thus delivering innovative solutions, at lower costs and with lower toxicities at both the surface and core of the wood, as is the case with lacquers or "stains" and fast-drying varnishes (AITIM 2012).

The final color of wood treated with Type-C micronized copper azole is a faint greenish color (LIGNUM 2014), which, compared with the CCA treatment, is less intense and mistakenly considered as a sign of bad or poor treatment. Even when the application of Type-C micronized copper azole is efficient, a negative impression is perceived in the marketplace, considering that a greenish color is a sign of properly treated wood. Adding a more attractive coloration to $\mu \mathrm{CA}-\mathrm{C}$ could improve market acceptance. Therefore, additional research is needed to identify new combinations of preservatives and sustainable, market-acceptable colors.

This new feature of color-treated wood can add decorative value and hide visual defects, such as stains, improving the range of raw materials used by treated wood producers, providing an aesthetic to outdoor woods (AITIM 2008).

When the wood is stained through processes, such as dye or tannic, protection against termite attack is low, according to Tascioglu et al. (2014) who evaluated the potential anti-termite properties of some common wood stains tested against Coptotermes formosanus. Four different wood species stain treated with 3 different chemicals at the $0,1 \mathrm{~kg} / \mathrm{m}^{2}$ retention level were exposed to the termite feeding no-choice test under laboratory conditions. The mean mass losses, mortality rates and consumption rates based on weight were calculated before and after the test, while the hardwood species (beech and chestnut) were unaffected by the treatments, and the softwood species showed dramatic losses in mass reductions in response to some staining treatments. Scots pine and spruce sapwood exhibited significant losses in mass reductions when treated with the chemical stain.

A change in the gloss of lasures is expected and is not a critical property to determine its effectiveness, as observed in varnishes (Garay 2007, 2008, 2009a, 2009b, 2009c, 2010, 2012, Dieguez 1994, Dieguez 1997). In the present study, the losses are reduced (3 to $4 \%$ ) for the commercial lasures studied, as this loss is presumed under outdoor conditions, and, therefore, these products are marketed as glossy or matte. During the test, thermal degradation, thermal fluctuations from day to night and moisture phenomena, which together foster physical and chemical changes in wood, such as vitrea transition temperature, were observed. A typical case is the exudation or migration of substances (resins) from wood product temperature increases, in response to exposure, generating brighter surfaces, although it is the same substrate, these phenomena occur in microzones, where there is increased presence of this substance.

Temiz et al. (2006) compared the copper emission rates from wood treated with chromated copper arsenate (CCA), alkaline copper quaternary (ACQ), Tanalith E and Wolmanit CX according to OECD guidelines. These authors reported that the percentage of copper leached from wood treated with alternative copper-based preservatives was higher than that of CCA-treated wood. Temiz et al. (2014) examined the leaching and decay resistance of alder and pine wood treated with copper-based wood preservatives, and the results suggested that CCA releases less copper than all other copper-based wood preservatives. This finding might reflect the fact that the copper in CCA is more strongly bonded than in some of the alternative wood preservatives, alternative formulations with a higher copper or different fixation mechanisms. The presence of a stain can help to reduce this leaching, although in the present study the leaching of copper was not determined. However, it is possible to infer, a priori, that the stain avoided to some undetermined extent, the leaching of preservatives.

Ghosh et al. (2015) examined the loss of gloss of shellac and polyurethane finishes exposed to UV, indicating that the coatings similar lost their gloss primarily in the first $40 \mathrm{hrs}$. Thereafter, the loss of gloss was rather uniform until the end of the experiment. Hence, the UV degradation, with respect to the gloss, primarily occurs during the initial period of exposure, with mean percentage reductions in gloss reflecting exposure to UV light of approximately 12 to $16 \%$.

The first part of the color change process reflects the formation of chromophoric groups, such as carbonyl and carboxyl groups, primarily resulting from the degradation of $\alpha$-carbonyl, biphenyl and ring-conjugated double bond structures in lignin and the transfer of the extractives from within to 
the surface of the wood (Lin and Kringstad 1970, Hon and Feist 1992). A relatively rapid change has been reported for wood material exposed to UV light in the external environment for a short period or under accelerated weathering (Feist and Hon 1984, Williams 2005, Peker et al. 2012). In this study, the greatest color change occurred at 200 hours, considered, at this time, as the highest concentration source of these chemical and physical changes in wood.

Yeniocak et al. (2015) used eco-friendly wood stained with extracts from beetroot (Beta vulgaris) and determined the color stability of this stain to UV light irradiation. Scots pine (Pinus sylvestris), oriental beech (Fagus orientalis), oak (Quercus petraea) and walnut (Juglans regia) wood specimens were used for this study. After treatment with stain, wood specimens were exposed to UV irradiation for periods of 50,100 and 150 hours. The results showed that the color change values for all wood specimens colored with beetroot extract had better performance compared with synthetic dye. Beetroot extracts can be used as an upper surface dyestuff for indoor application and toys. Therefore, wood paints could be developed as more economical and eco-friendly alternatives to synthetic dyes.

Moreover, Lebow (2014) reported a challenge to assessment procedures in a study of the effects of precipitation pattern on the leaching of preservative from treated wood and implications for accelerated testing, expressing concern for the methods used to evaluate the leaching of wood preservatives, an aspect which was not considered in this study. However, to some extent, the loss of the stain color might reflect product weatherability. Lebow suggested that although the study intended to simulate in-service leaching, this approach might not represent commercially produced lumber (Baines 2005) or produce the moisture conditions reported for wood products exposed to natural weathering (Lebow et al. 2008). A study comparing outdoor leaching to the OECD method concluded that the laboratory method risked underestimating in-service leaching (Morsing and Lindegaard 2004).

Archer provided evidence that copper retards photodegradation. Lignin forms free radicals (phenoxils) (Archer 2006), which interact with copper to form a phenolate, retarding the appearance of phenoxy-type free radicals involved in the color change (Kamdem and Grelier 2002).

The objective of the present study was to evaluate the color and gloss characteristics of decorative protection applied to wood for exterior use and treated with Type-C micronized copper azole. Were measured the variables of gloss and color of six decorative protections applied to wood for exterior use, by testing natural and accelerated aging. Also were calculated the costs based on performance per surface covered and each decoration protection applied to treated wood for outdoor use, compared with two alternative coatings available on the market.

\section{MATERIALS AND METHODS}

\section{Materials}

\section{Substrate and Protection}

The substrate used in both tests was Pinus radiata (D. Don.) treated with micronized copper plus tebuconazole and propyconazole $(\mu \mathrm{CA}-\mathrm{C})$, also known as Type-C micronized copper preservative, at $3,08 \mathrm{~kg} / \mathrm{m}^{3}$, risk class $3(\mathrm{R} 3)$, based on use and risk in service NCH 819, 2012. (Manufacturer's ArchQuimetal Ltda. Chile, a company associated with Arch Wood Protection).

Three commercial products were used, namely, industrially applied colored lacquers, used according to the manufacturers' instructions, and the control samples, corresponding to wood treated with Type-C micronized copper azole. Additionally, two commercial varnishes were applied on treated and non-treated radiate pine control samples (Table 1). 
Table 1. Description of treatments included in the test.

\begin{tabular}{|l|l|l|}
\hline Treatments: & Treatment Description & Treatment Number \\
\hline T1 & Non-treated radiate pine wood $(\mathrm{M} \mathrm{I})$ & Reference \\
\hline T2 & M I treated with $\mu$ CA-C at $3,08 \mathrm{~kg} / \mathrm{m}^{3}$ & 1 \\
\hline T3 & M I $\mu$ copper azole and Prestain P at $8 \%$ & 2 \\
\hline T4 & M I $\mu$ copper azole and Red Cylinder at $1 \%$ & 3 \\
\hline T5 & M I $\mu$ copper azole and Black Cylinder at $1 \%$ & 4 \\
\hline T6 & M I $\mu$ copper azole and water-based varnish & 5 \\
\hline T7 & M I $\mu$ copper azole and solvent-based varnish & 6 \\
\hline
\end{tabular}

\section{Infrastructure}

The facilities of the Wood Technology Center, School of Forestry Sciences, University of Chile, were used for the preparation of the samples and the treatment and application of the colored coating. The natural aging tested specimens were installed at the Department of Wood and Bio-Materials Engineering. The test was conducted at 0,1,2 and 3 months of North and South exposure.

\section{METHODS}

The methodology included the assessment of the color and gloss decoration features of the protection applied to the wood samples treated with Type-C micronized copper azole, according to the manufacturer's instructions. The samples were subjected to outdoor tests (natural aging) for three months and laboratory tests using Type-B UV light irradiation at a wavelength of $340 \mathrm{~nm}$ (accelerated aging) for 500 hours.

\section{Variables assessed}

Both trials were evaluated using a glossmeter and datacolor, Gloss Mitter BYK, with an incidence angle of $60^{\circ}$ and a Datacolor 650 color meter, with corporate ORION software.

Gloss Variation (ISO 2813:1994). To determine the gloss variation, a gloss measurement device was used, with an incidence angle value of $60^{\circ}$, which measures the reflectance degrees (reflected gloss). The gloss loss average value was calculated for the exposed samples (LG ex) and the reference samples (LG ref).

The gloss variation was calculated based on the difference between these two parameters:

$$
\% \text { gloss variation }=L G=(L G \text { ex }-L G \text { ref })
$$

Color Difference $\Delta \mathrm{E}$ (ISO 7724:1997). Measurements were made on CIELAB coordinates, which determine the color difference between the initial standard as a reference and the tested sample after three months. The measurements were obtained using a Datacolor 650 color meter and ORION software.

The color variation was measured in CIELAB coordinates for determining the color difference $\left(\Delta \mathrm{E}^{*}\right)$ between a standard used as a reference and the tested sample, achieved using a Data Color colorimeter, which records data on a computer. The illuminating light D65, which describes the average conditions of lighting during the mid-day in Europe (data that is delivered by default in the colorimeter), was considered. The CIELAB (CIE L *a *b ) coordinates derived from the color model were used to describe the colors that the human eye can perceive (objectively) and expressed in numerical terms or in a spectral reflectance graph. The CIELAB comprises the following three coordinates: 
$\mathrm{L}^{*}=$ brightness $(+$ light $=$ white,- light $=$ black $)$

$\mathrm{a}^{*}=\mathrm{red} /$ green coordinate (+indicates red, -a indicates green)

$\mathrm{b}^{*}=$ yellow/blue coordinate $(+\mathrm{b}$ indicates yellow, blue indicates $-\mathrm{b})$.

The color difference between two samples was represented as the parameter $\Delta \mathrm{E}^{*}$ calculated as:

$$
\Delta E^{*}=\sqrt{\left((\Delta L)^{2}+\right)(\Delta a)^{2}+(\Delta b)^{2}}
$$

Where $\Delta L$ is the difference between $\left(L_{i}-L_{f}\right), \Delta a$ is the difference between $\left(a_{i}-a_{f}\right)$ and $\Delta b$ is the difference between $\left(b_{i}-b_{f}\right)$. It is the initial measurement and $\mathrm{f}$ is the final measurement. Levels of perceived color difference.

Positive values of $\Delta L^{*}$ show whitening, and negative values of $\Delta L^{*}$ indicate a shift toward gray. Positive values of $\Delta a^{*}$ indicate reddening, and negative values of $\Delta a^{*}$ show a shift towards green. Positive values of $\Delta b^{*}$ represent yellowing, and negative values of $\Delta b^{*}$ represent a shift towards blue.

The $\Delta \mathrm{E}$ parameter*, defined according to the classification of Hikita et al (2001), is as follows:

$\Delta \mathrm{E} *$ Varies from 0 to 0,5 the color is negligible change

$\Delta \mathrm{E}^{*}$ Ranges from 0,5 to 1,5 is slightly perceptible.

$\Delta \mathrm{E} *$ Ranges from 1,5 to 3,0 is barely noticeable on the surface.

$\Delta \mathrm{E} *$ Ranges from 3,0 to 6,0 is appreciable.

$\Delta \mathrm{E} *$ Ranges from 6,0 to 12 is very significant

\section{Substrate Preparation:}

The surface of the samples was flat, smooth, planed but not sanded, at $12 \% \mathrm{CH}$, as per the indications contained in Norm EN 927-3, which establishes the use of samples for natural aging assays, with a tangent cut of $300 \mathrm{~mm} \times 80 \mathrm{~mm} \times 20 \mathrm{~mm}$, sapwood only, and accelerated aging assays, with sample dimensions of $150 \mathrm{~mm} \times 80 \mathrm{~mm} \times 0.7 \mathrm{~mm}$.

For impregnated wood, we employed a vacuum pressure treatment cylinder $0,1964 \mathrm{~m}^{3}$; micronized copper, plus tebuconazole and propyconazole $(\mu \mathrm{CA}-\mathrm{C})$ at $3,08 \mathrm{Kg} / \mathrm{m}^{3}$; a pressure pump, $10 \mathrm{~kg} / \mathrm{cm}^{2}$; and an immersion tub. For the application of protection, a roller and solution container were used. The samples were prepared by groups and duly identified in flasks containing the appropriate solution, avoiding floating through a metal mesh and with enough solution to maintain exposure to the air during the process. The bottles possessed upper opening to enable air flow, arranged in an autoclave under an initial vacuum of $-0,6$ Bar $(-17,7$ ' $\mathrm{Hg}$ ) to maintain the vacuum for one hour. Subsequently, the air valve was opened to atmospheric pressure. The air was injected under an internal pressure of $30 \mathrm{psi}(2,1 \mathrm{~kg} /$ $\mathrm{cm}^{2}$ ), which was maintained for a period of four hours. The valves were closed, and the specimens were left inside overnight (14 hours). The next day, the samples were removed and the non-buoyancy of the samples was confirmed. The surface was dried with an absorbent paper and weighed (P2). Impregnation was pretested with water to corroborate the absorption rate, which was between $100-105 \%$ of the initial weight (P1). The withholding preservative $\left(\mathrm{kg} / \mathrm{m}^{3}\right)$ was calculated using the following formula: 


$$
\text { Retention }\left(\mathrm{kg} / \mathrm{m}^{3}\right)=(G C / V)
$$

Where:

$\mathrm{G}=(\mathrm{P} 2-\mathrm{P} 1)=$ grams of treating solution absorbed by the block (block to the initial weight before treatment of the initial weight subtracted more treating solution absorbed).

$\mathrm{C}=$ grams of preservative in $100 \mathrm{~g}$ of treating solution and $\mathrm{V}=$ volume of the block $\mathrm{cm}^{3}$.

$$
\begin{aligned}
& \text { Sample Vol. }=0,0001984 \mathrm{~m}^{3} \\
& \text { Weight difference }=80,595081 \text { grams } \\
& \text { Gross absorption }=0,080595081 \mathrm{kilos} \text { or liters } \\
& \text { Net Absorption }=406,2252067 \mathrm{kilos} / \mathrm{m}^{3} \\
& \text { Concentration }=0,007582001 \mathrm{kilos} / \mathrm{liter} \\
& \text { Concentration }(\%)=0,758200119 \mathrm{p} / \mathrm{v}
\end{aligned}
$$

After the blocks were impregnated and their weights were set to obtain the absorbed volume, these groups were exposed to laboratory conditions for $48 \mathrm{~h}$ and, subsequently, transported to a conditioning chamber at $26{ }^{\circ} \mathrm{C}$ and $70 \%$ relative humidity. This procedure lasted 21 days, and subsequently the specimens were weighed (P3) to $0,01 \mathrm{~g}$ and the initial dry weight was determined at a $\mathrm{CH}$ of $16 \% \pm 1 \%$. Subsequently, the surface treatments were applied according to manufacturer's instructions.

Prior to exposure, each sample was controlled in terms of mass (by weight), and percentage of gloss and color, using measurement instruments and taking pictures as a reference. These data were used as the starting point for the test, assuming no gloss variations or color variations in the treatment samples at the zero time. Protection was applied according to the manufacturer's instructions to condition the samples until the moisture contents were balanced.

Each test was conducted using a unique methodology, and, therefore, the descriptions are provided separately.

\section{Accelerated Aging Test}

This test is based on standard UNE-EN-ISO 11507, of 1997 Accelerated Aging. The artificial aging and color and gloss change measurements were conducted at the Sherwin Williams Laboratory in Chile. A QUV chamber, with fluorescent lights of 0,55 watts $/ \mathrm{m}^{2} /$ hour emission of Type-B and UV rays, with a wavelength of $340 \mathrm{~nm}$, was used. A total of twenty-eight $150 \times 80 \times 10 \mathrm{~mm}$ samples (4 per treatment) were used, and 4 samples were used as a pattern. The UV exposure measurements were conducted at $0,100,200,300,400$ and 500 hours.

\section{Natural Aging Test}

This test is based on the EN 927, part 3: Natural aging-Paint Coatings and Varnishes. Outdoor Wood Coating Materials and Systems, which assesses the coating systems resistance to natural aging and determined changes in decoration and protection properties of the coatings after six months of north and south exposure. The natural aging test was conducted at Wood Engineering Department of Science Forestry of the University of Chile in Santiago, Chile, between March and May of 2014.

The basic equipment required for the test were a wooden sawbuck with inclination at an angle of $45^{\circ}$ in relation to the horizontal, oriented towards the north and south. Others implements, such as a 12 megapixel camera and a balance with a capacity of $500 \mathrm{~g}$ and an accuracy of $0,01 \mathrm{~g}$, were used. 
A total of 42 samples were mounted on sawbucks with an inclination of $45^{\circ}, 21$ samples with northern exposure, ( 7 treatment samples with 3 repetitions each one) and 21 treatment samples with southern exposure.

To fulfill the objectives of the present study, the aesthetic color and gloss characteristic variations resulting from UV rays were determined, and the parameters measured gloss variation percentages $(\% \mathrm{GU})$ and color difference $\Delta \mathrm{E}$, using a gloss measurement device and a color meter for three months.

The measurements were obtained at the start of the test and after three months of outdoor exposure, with an up-to-date total of the two measurements. Each measurement controlled the gloss percentage and color difference.

\section{RESULTS}

\section{Gloss and Color Aesthetic Features}

Test conducted for artificial aging (EA) through exposure to UV rays at a 340-nm wavelength for 500 hours

The table 2 shows the Treatment T1: Untreated radiata pine, reference: (T11- T14 repetitions).

Table 2. Treatment T1: Untreated radiata pine, reference: (T11- T14 repetitions).

\begin{tabular}{|c|c|c|}
\hline \multirow{2}{*}{ Time (h) } & ${\text { Gloss }<\mathbf{6 0}^{\circ}}^{\text {C Color Delta E }}$ \\
\cline { 2 - 3 } & $\mathbf{T 1}$ & T1 \\
\hline 0 & $4,9 \%$ & 0,00 \\
\hline 100 & $4,7 \%$ & 14,04 \\
\hline 200 & $4,5 \%$ & 28,07 \\
\hline 300 & $4,9 \%$ & 17,00 \\
\hline 400 & $5,1 \%$ & 18,17 \\
\hline 500 & $5,3 \%$ & 18,29 \\
\hline
\end{tabular}

Figures 1 and 2 show an increase in the gloss percentage of $0,4 \%$ and a color difference $\Delta \mathrm{E}=18,29$ for samples at time 0 and after 500 hours.

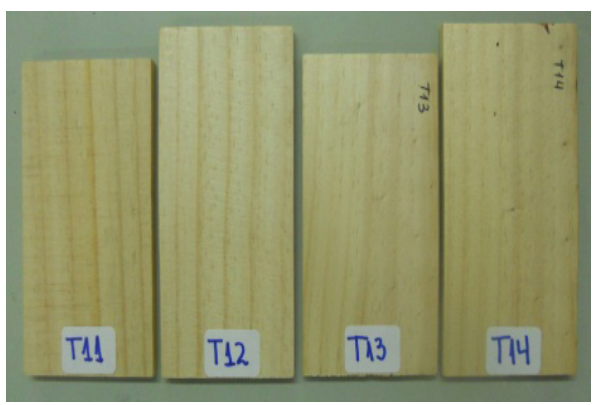

Figure 1. Treatment T1. (Time: 0 hours).

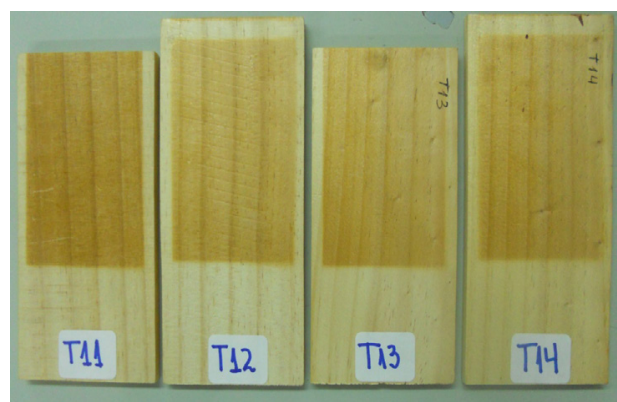

Figure 2. Treatment T1. (Time 500 hours).

Table 3 shows treatment T2 Radiata pine treated with micronized copper plus tebuconazole and 
propyconazole, at 3,08 kg/m³ class R3 (T21 -T24 repetitions).

Table 3. Treatment $\mathrm{T} 2$ : Radiata pine treated with micronized copper plus tebuconazole and propyconazole, at 3,08 kg/m³ , class R3 (T21 -T24 repetitions).

\begin{tabular}{|c|c|c|}
\hline \multirow{2}{*}{ Time (hours) } & ${\text { Gloss }<\mathbf{6 0}^{\circ}}^{\circ}$ & Color $\Delta \mathbf{E}$ \\
\cline { 2 - 3 } & $\mathbf{T 2}$ & T2 \\
\hline 0 & $2,9 \%$ & 0,00 \\
\hline 100 & $2,6 \%$ & 15,45 \\
\hline 200 & $2,3 \%$ & 30,91 \\
\hline 300 & $2,5 \%$ & 18,65 \\
\hline 400 & $2,9 \%$ & 20,01 \\
\hline 500 & $2,9 \%$ & 20,95 \\
\hline
\end{tabular}

Figures 3 and 4 shows that the gloss percentage is $0 \%$, and the color difference $\Delta \mathrm{E}$ is 20,95 from Time 0 through 500 hours.

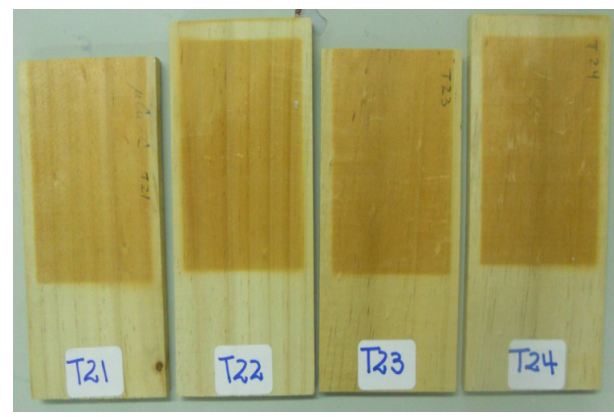

Figure 3. Treatment T2. (Time 0 hours).

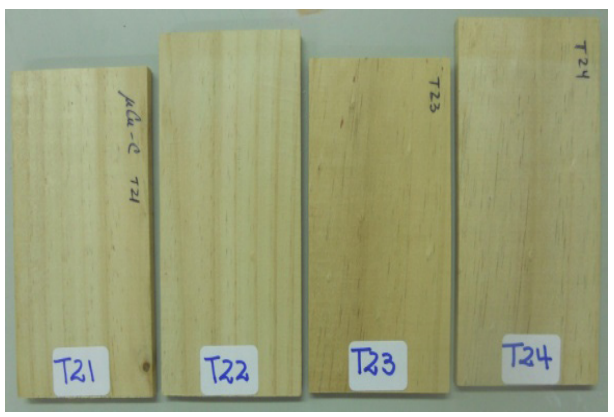

Figure 4. Treatment T2. (Time 500 hours).

Table 4 shows the Treatment T3: Radiata pine treated with micronized copper plus tebuconazole and propyconazole and Prestain P at 8\% (T31 -T34 repetitions).

Table 4. Treatment T3: Radiata pine treated with micronized copper plus tebuconazole and propyconazole and Prestain P at 8\% (T31 -T34 repetitions).

\begin{tabular}{|c|c|c|}
\hline \multirow{2}{*}{ Time (hours) } & ${\text { Gloss }<\mathbf{6 0}^{\circ}}^{\text {C }}$ & Color Delta E \\
\cline { 2 - 3 } & $\mathbf{T 3}$ & T3 \\
\hline 0 & $0,8 \%$ & 0,00 \\
\hline 100 & $0,8 \%$ & 1,80 \\
\hline 200 & $0,7 \%$ & 3,61 \\
\hline 300 & $0,7 \%$ & 1,76 \\
\hline 400 & $0,7 \%$ & 1,53 \\
\hline 500 & $0,7 \%$ & 1,45 \\
\hline
\end{tabular}

Figures 5 and 6 show that the gloss percentage decreased $0,1 \%$ at the end of the assay and the color change $\Delta \mathrm{E}$ was 1,45 from Time 0 to 500 hours. 


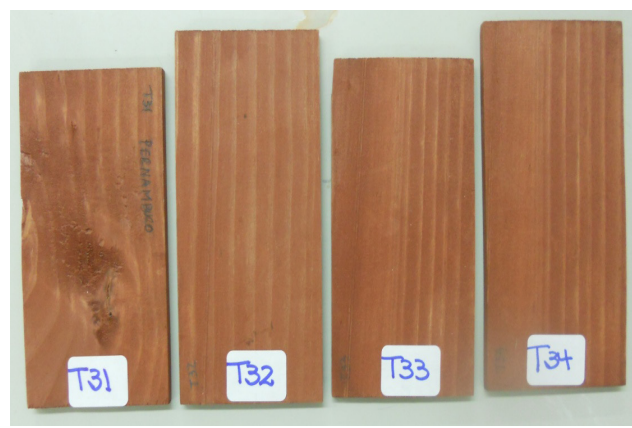

Figure 5. Treatment T3. (Time 0 hours).

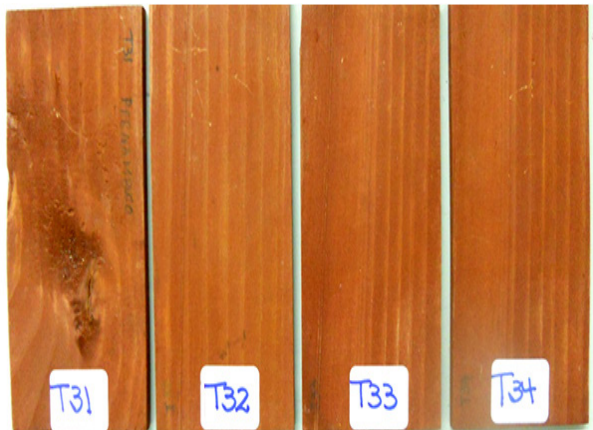

Figure 6. Treatment T3. (Time 500 hours).

The table 5 shows the Treatment T4: Radiata pine wood treated with micronized copper plus tebuconazole and propyconazole, and Red Cylinder at 1\% in mixture (T41 -T44 repetitions).

Table 5. Treatment T4: Radiata pine wood treated with micronized copper plus tebuconazole and propyconazole, and Red Cylinder at 1\% in mixture (T41 -T44 repetitions).

\begin{tabular}{|c|c|c|}
\hline \multirow{2}{*}{$\begin{array}{c}\text { Time } \\
\text { (hrs.) }\end{array}$} & ${\text { Gloss }<\mathbf{6 0}^{\circ}}$ & Color Delta E \\
\cline { 2 - 3 } & $\mathbf{T 4}$ & $\mathbf{T 4}$ \\
\hline 0 & $1,8 \%$ & 0,00 \\
\hline 100 & $2,7 \%$ & 9,68 \\
\hline 200 & $3,5 \%$ & 19,36 \\
\hline 300 & $3,2 \%$ & 13,22 \\
\hline 400 & $3,6 \%$ & 13,95 \\
\hline 500 & $3,6 \%$ & 13,47 \\
\hline
\end{tabular}

Figures 7 and 8 show a 1,8\% increase in the gloss percentage and a color difference $\Delta \mathrm{E}$ of 13,47.
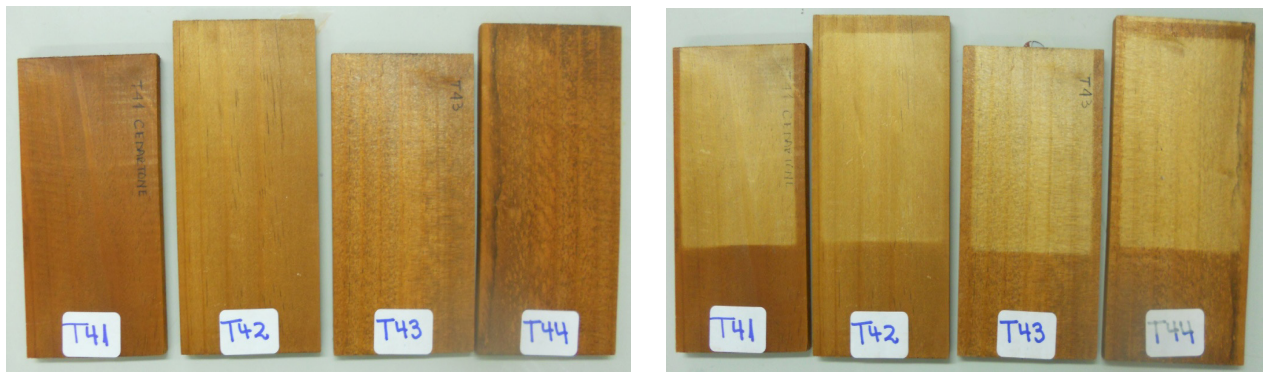

Figure 7. Treatment T4. (Time 0 hours).

Figure 8. Treatment T4. (Time 500 hours).

The table 6 shows the Treatment T5: Radiata pine treated with micronized copper plus tebuconazole and propyconazole, and 1\% Black Cylinder in the mixture (T51 -T54 repetitions). 
Table 6. Treatment T5: Radiata pine treated with micronized copper plus tebuconazole and propyconazole, and 1\% Black Cylinder in the mixture (T51 -T54 repetitions).

\begin{tabular}{|c|c|c|}
\hline \multirow{2}{*}{ Time (hours) } & ${\text { Gloss }<\mathbf{6 0}^{\circ}}^{\circ}$ & Color Delta E \\
\cline { 2 - 3 } & $\mathbf{T 5}$ & T5 \\
\hline 0 & $1,1 \%$ & 0,00 \\
\hline 100 & $1,2 \%$ & 2,76 \\
\hline 200 & $1,3 \%$ & 5,52 \\
\hline 300 & $1,2 \%$ & 3,26 \\
\hline 400 & $1,3 \%$ & 3,44 \\
\hline 500 & $1,3 \%$ & 3,58 \\
\hline
\end{tabular}

Figures 9 and 10 show a $0,2 \%$ increase in the gloss percentage and a color difference $\Delta \mathrm{E}$ of 3,58 .
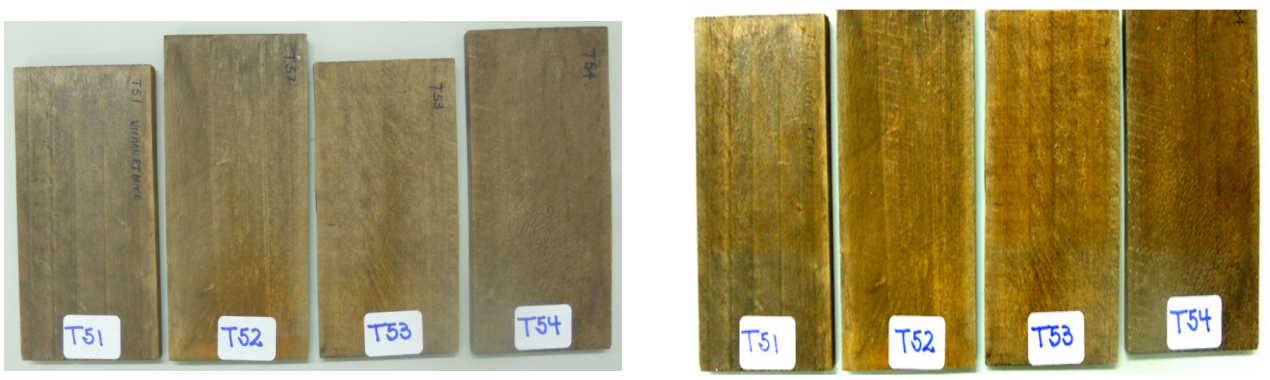

Figure 9. Treatment T5. (Time 0 hours).

Figure 10. Treatment T5. (Time 500 hours).

The table 7 shows the Treatment T6: Radiata pine treated with micronized copper plus tebuconazole and propyconazole and water-based varnish, after treatment. (T61 -T64 repetitions).

Table 7. Treatment T6: Radiata pine treated with micronized copper plus tebuconazole and propyconazole and water-based varnish, after treatment. (T61 -T64 repetitions).

\begin{tabular}{|c|c|c|}
\hline \multirow{2}{*}{ Time (h) } & ${\text { Gloss }<\mathbf{6 0}^{\circ}}^{\circ}$ & Color Delta E \\
\cline { 2 - 3 } & $\mathbf{T 6}$ & T6 \\
\hline 0 & $37,4 \%$ & 0,00 \\
\hline 100 & $36,4 \%$ & 13,20 \\
\hline 200 & $35,4 \%$ & 26,40 \\
\hline 300 & $37,3 \%$ & 15,08 \\
\hline 400 & $33,6 \%$ & 15,73 \\
\hline 500 & $33,7 \%$ & 16,47 \\
\hline
\end{tabular}

Figures 11 and 12 show a 3,7\% decrease in gloss percentage and a color variation $\Delta \mathrm{E}$ of 16,47 . 


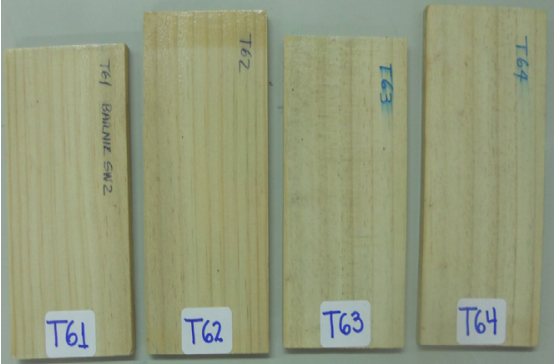

Figure 11. Treatment T6. (Time 0 hours)

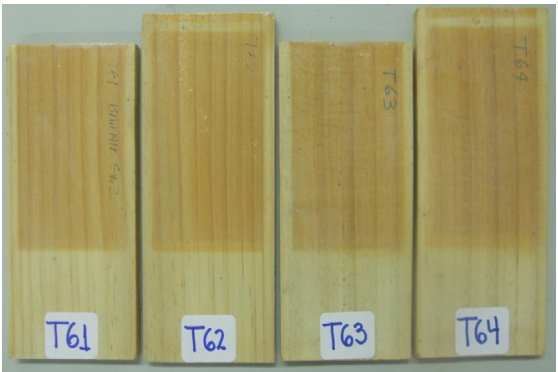

Figure 12. Treatment T6 (Time 500 hours)

The table 8 shows the Treatment T7: Radiata pine treated with micronized copper plus tebuconazole and propyconazole, and SW solvent-based varnish, after treatment. (T71 -T74 repetitions).

Table 8. Treatment T7: Radiata pine treated with micronized copper plus tebuconazole and propyconazole, and SW solvent-based varnish, after treatment. (T71 -T74 repetitions).

\begin{tabular}{|c|c|c|}
\hline \multirow{2}{*}{ Time (h) } & ${\text { Gloss }<\mathbf{6 0}^{\circ}}^{\circ}$ & Delta E (Cielab) \\
\cline { 2 - 3 } & $\mathbf{T 7}$ & $\mathbf{T 7}$ \\
\hline 0 & $38,7 \%$ & 0,00 \\
\hline 100 & $38,0 \%$ & 8,97 \\
\hline 200 & $37,3 \%$ & 17,94 \\
\hline 300 & $35,7 \%$ & 12,38 \\
\hline 400 & $35,5 \%$ & 15,50 \\
\hline 500 & $37,5 \%$ & 16,70 \\
\hline
\end{tabular}

Figures 13 and 14 show a 1,2\% decrease in the gloss percentage and a color difference $\Delta \mathrm{E}$ of 16,7 .

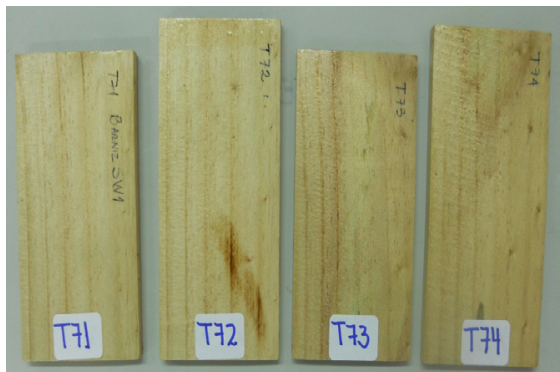

Figure 13. Treatment T7 (Time 0 hours).

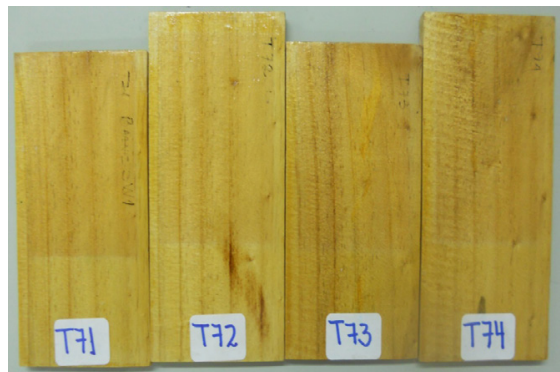

Figure 14. Treatment T7 (Time 500 hours).

\section{Natural Aging Test (EN)}

\section{Gloss and color aesthetic features after three months}

Figures 15 and 16 show a general view of the natural aging assay installed in Santiago, Chile at the beginning and after 90 days. 


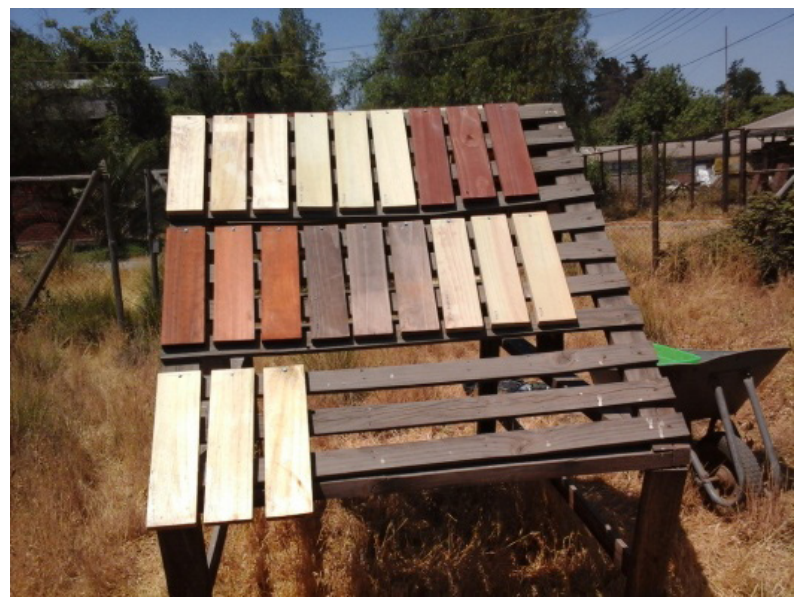

Figure 15. Natural aging Time $0(\mathrm{~N})$.

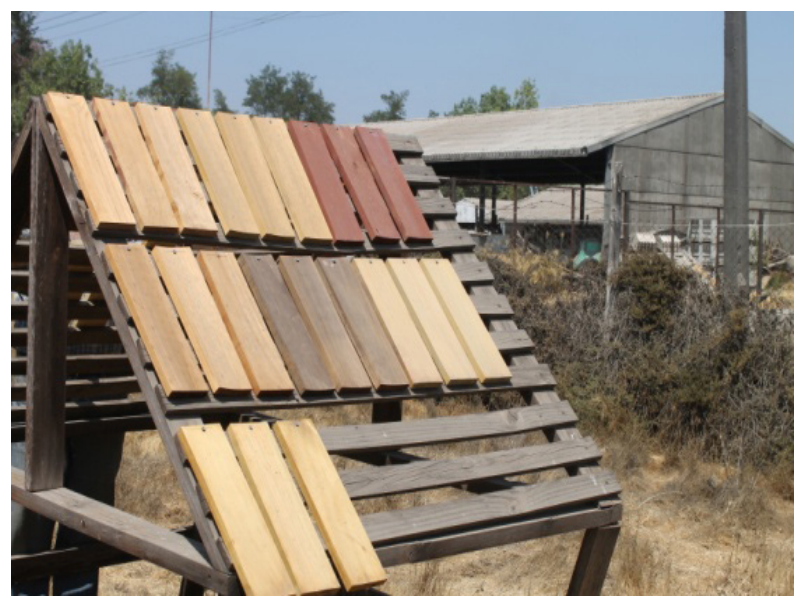

Figure 16. Natural aging 90 days exposure (T3).

\section{ANALYSIS AND DISCUSSION OF THE RESULTS}

\section{Accelerated Aging Test (EA), UV radiation for 500 hours}

\section{Variation in gloss percentage and Variation in Color $\Delta \mathrm{E}$}

Figure 17 shows that the lowest percentage of gloss loss between the beginning and the end of the treatment occurred in treatment T3, corresponding to Prestain P, with $0,1 \%$ loss, followed by treatment $\mathrm{T} 7$, the solvent-based varnish, with $1,2 \%$ gloss loss, and finally $\mathrm{T} 6$, with a $3,7 \%$ loss, reflecting the anti-froth products present in fast-drying varnishes (verbal communication with $\mathrm{SW}$ ). 


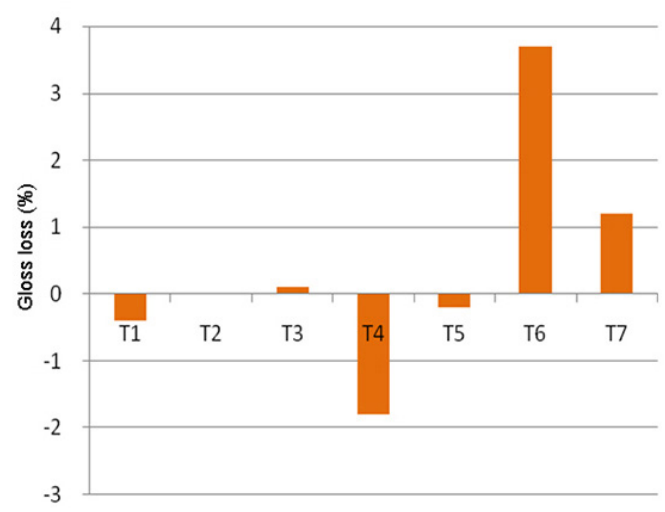

Figure 17. Gloss loss and increase (\%) for 500 hours

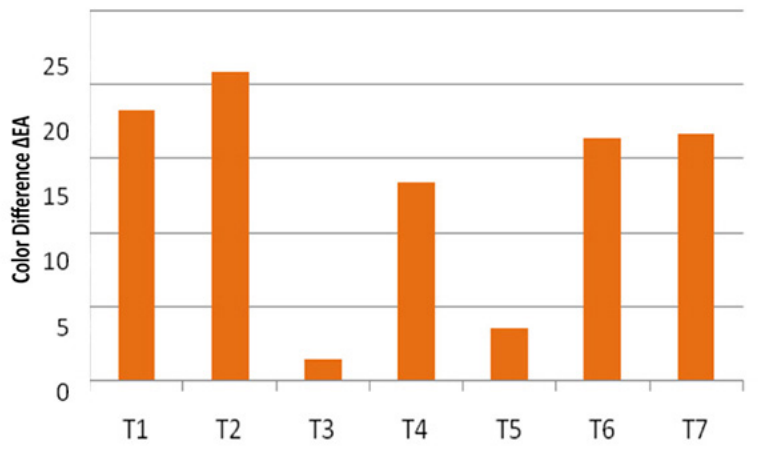

Figure 18. Difference in color $\Delta \mathrm{E}$ (Cielab) for 500 hours.

The highest percentage of gloss increase occurred in T4, corresponding to the decoration protection Red Cylinder, with a value of $-1,8 \%$ followed by reference treatment $\mathrm{T} 1$, with $-0,4 \%$, corresponding to treated pine, with a $1,8 \%$ gloss increase, and treatment $\mathrm{T} 5$, with $-0,2 \%$ treated with protection Black Cylinder.

Notably, the gloss percentage remained unchanged after 500 hours in the case of control sample $\mathrm{T} 2$, corresponding to pine treated with micronized copper azole and no coating.

Figure 18 shows that decoration protection with least color variation are the Prestain $\mathrm{P}$ treatment (T3) with $\Delta \mathrm{E}=1,45$ and Black Cylinder (T5) with a value of $\Delta \mathrm{E}=3,58$.

The maximum color variation, equivalent to 20,95 occurred in control treatment T2. Subsequently, treatments with varnish show similar color variation ranges, where treatment with solvent-based varnish $\mathrm{T} 7$ presents a $\Delta \mathrm{E}$ of 16,70 and treatment with water-based varnish $\mathrm{T} 6$ presents a $\Delta \mathrm{E}$ of 16,47 . Treatment with protective Red Cylinder T4 presents a color difference $(\Delta \mathrm{E})$ of 13,47.

With respect to the increase in gloss and color that where observed at 200 hours of exposure, more studies are needed, but it might be due to the surface degradation which intensifies these parameters, particularly in a matte-finished product. 
Cui et al. (2004) established that for $\Delta \mathrm{E}<6$, color changes are not negligible, and, therefore, only Prestain P (T3) and Black Cylinder (T5) treatments would be included in this category.

\section{Natural Aging Test (three months)}

\section{Variation in Gloss in \% (loss) and Color Difference $\triangle E$ (CIELAB Coordinates)}

Figure 19 shows that the least variations in terms of percentage of gloss loss corresponded to treatment T3 (Prestain P), with a value of $0,55 \%$ followed by T5 (Black Cylinder), with a value of $0,75 \%$ and $\mathrm{T} 4$ (Red Cylinder) with $0,78 \%$ gloss loss.

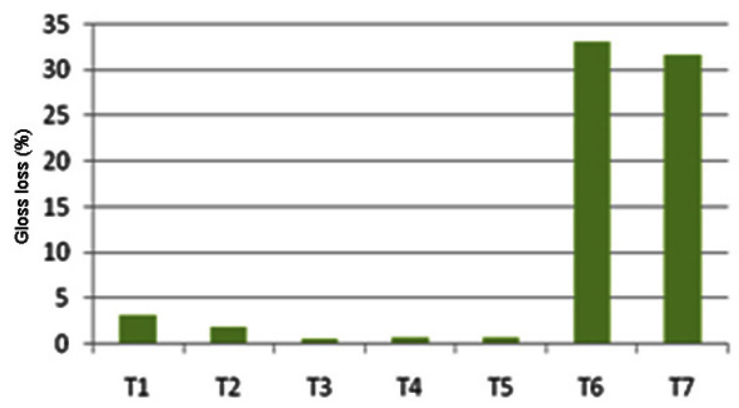

Figure 19. Gloss loss (\%) at three months.

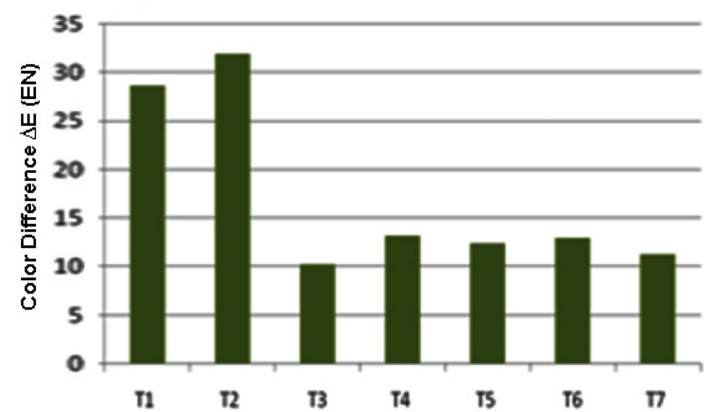

Figure 20. Color difference $(\Delta \mathrm{E})$ at three months.

Maximum gloss loss percentages correspond to treatment T6 (water-based varnish) with $33,12 \%$ T7 (solvent based varnish) with $31,7 \%$ and the control treatment (T2), with a value of $1,85 \%$ surpassed by reference treatment $\mathrm{T} 1$, with $3,23 \%$ corresponding to untreated pine.

Figure 20 shows that the smallest color differences correspond to treatment T3 (Prestain P), with a $\Delta \mathrm{E}$ of 10,26 followed by T7 (solvent-based varnish) with a $\Delta \mathrm{E}$ of 11,24 and T5 (Black Cylinder), with a $\Delta \mathrm{E}$ of 12,41 . 
The maximum color differences correspond to treatments $\mathrm{T} 2$ (control) with a $\Delta \mathrm{E}$ of 31,85 which exceeds the reference treatment $\mathrm{T} 1$ with a $\Delta \mathrm{E}$ of 28,54 followed by T4 (Red Cylinder), with a $\Delta \mathrm{E}$ of 13,16 and $\mathrm{T} 6$ (water-based varnish), with a $\Delta \mathrm{E}$ of 12,99 .

\section{Cost analysis}

These values consider dye consumption and the investments required for application on the wood, amortized over five years and a monthly output of $500 \mathrm{~m}^{3}$.

The increased cost to the impregnated wood would be $14 \%$ for prestain P coating, an increase of $17 \%$ for Black cylinder decorative coating and $21 \%$ for Red cylinder.

Table 9. Costs of in situ-to wood-applied decorative coatings.

\begin{tabular}{|c|c|c|}
\hline COSTS & T7 & T6 \\
\hline $\mathrm{M}^{2} /$ GALON & 35 & 35 \\
\hline USD/GALON & 26 & 33 \\
\hline USD/M2 & 0,74 & 0,95 \\
\hline $\mathrm{M}^{3} /$ PIECE & 0,00072 & 0,00072 \\
\hline $\mathrm{M}^{2} / \mathrm{PIECE}$ & 0,036 & 0,036 \\
\hline $\mathrm{USD} / \mathrm{PIECE}$ & 0,02653 & 0,03416 \\
\hline USD/M & $\mathbf{3 7}$ & $\mathbf{4 7}$ \\
\hline
\end{tabular}

Table 9 shows that the lowest cost of in situ-to-wood-applied coatings corresponds to solventbased varnish (T7) with a value of $37 \mathrm{US} \$ / \mathrm{m}^{3}$ (the best performance in gloss and color among all in situ coatings). This value does not consider the workforce cost to apply the product onto the wood.

The cost analysis for industrially applied decorative coatings showed that the prestain P (T3) decorative coating increases the value of the impregnated wood 14\%, and the cylinder black (T5) decorative coating increases the value $17,5 \%$ (Table 10), but the final user has no installation costs.

Table 10. Costs of industrially applied decorative wood coatings .

\begin{tabular}{|c|c|c|c|}
\hline COSTS & T3 & T5 & T4 \\
\hline $\mathrm{US} \$ \mathrm{~m}^{3}$ & 30 & 35 & 43 \\
\hline
\end{tabular}

Cost analysis for in situ-applied decorative coatings shows that the treatment with solvent based varnish (T7) increases the value of the impregnated wood $18,4 \%$ and for the water-based varnish treatment (T6) the value of impregnated wood increases $23,7 \%$ (Table 9).

Moreover, a cost-per-unit study was calculated, for the most used facade claddings in the country, such as fiber cement siding, vinyl siding and wood siding (wood paneling). The values were complemented with the results from this study to show that the impregnated wood decking treated with Prestain P is highly competitive, close in cost to vinyl siding and nearly $33 \%$ cheaper than fiber cement (Table 11). 
Table 11. Comparative costs between claddings, installed on a $1-\mathrm{m}^{2}$ wall façade.

\begin{tabular}{|c|c|c|c|}
\hline Estimated Cost & $\begin{array}{c}\text { Vinyl } \\
\text { Siding }\end{array}$ & $\begin{array}{c}\text { Wood } \\
\text { Siding }\end{array}$ & $\begin{array}{c}\text { Fiber Cement } \\
\text { Siding }\end{array}$ \\
\hline $1 \mathrm{~m}^{2}$ wall structure & 32 & 32 & 32 \\
\hline coating & 17 & 18 & 43 \\
\hline Total & 49 & 50 & 75 \\
\hline
\end{tabular}

Considering the costs, calculations were made for treatments showing better performance in terms of gloss loss and color differences, namely, Prestain P (T3) and Black Cylinder (T5). These values were compared against the following two competitor products: fiber cement siding and vinyl siding.

The results showed that, among the three decorative coatings industrially applied to wood through impregnation, those with best performance, i.e., increased permanence in decorative gloss and color and lower cost, were Prestain P (T3), followed by Black Cylinder (T5), whereas the T4 treatment (cylinder red) did not meet the desirable characteristics of gloss and color; therefore, this treatment was discarded as a recommendation.

Between the two decorative coatings applied in situ onto impregnated wood, which have better

performance in gloss and color retention features, with solvent-based varnish (T7) showed the lowest cost.

\section{CONCLUSIONS}

In the UV radiation exposure test, the treatments with the decoration coatings with the least difference in gloss for wood treated with micronized copper azole correspond to the application of Prestain P (T3), followed by Cylinder Black (T5).

In the accelerated aging UV radiation exposure treatments (EA), the treatments with the decoration coatings with the least color difference $(\Delta \mathrm{E})$ for wood treated with micronized copper azole correspond to the application of Prestain P (T3), followed by Black Cylinder (T5).

In the natural aging test (EN), the percentage of gloss loss in the case of Prestain P treatments (T3) and Black Cylinder (T5) showed the lowest values. The color differences with the least changes were achieved with the Prestain P treatments (T3), solvent-based varnish (T7), and Black Cylinder (T5).

When comparing the costs of these alternative coatings for facades installed per $\mathrm{m}^{2}$, the costs of industrially colored impregnated wood suggested that treatment with Prestain P (T3) is the most efficient option, i.e., the lowest cost per $\mathrm{m}^{2}$, followed by Black cylinder (T5), solvent-based varnish decorative coating (T7), and water-based varnish (T6), including the implementation costs of labor. The final options are vinyl siding and unpainted fiber cement siding.

\section{ACKNOWLEDGMENTS}

The authors would like to thank Sherwin Williams for use of the laboratory facilities and ArchQuimetal for support in the development of this research. 


\section{REFERENCES}

Archer, K.; Peston, A. 2006. An overview of copper based wood preservatives. Wood protection, http://www.forestprod.org/woodprotection06archer.pdf.

AITIM. 2012. News of the wood protection. 62nd Assembly of European industrial sector of wood protection Technical Bulletin No272, p. 42-45.

Asociación de Investigación técnica de las Industrias de la Madera. AITIM. 2008. Coloring wood in autoclave. Technical Bulletin No. 253, page 25.

Asociacion Española De Normalizacion y Certificación. AENOR. 1997. Paints and varnishes. Coating materials and coating systems for exterior wood. Part 3: Test of Natural Aging. EN 927-3.

Asociacion Española De Normalizacion y Certificación. AENOR. 2002. UNE-EN-ISO 11507. Paints and varnishes. Exposure of coatings to artificial aging. Fluorescent exposure to ultraviolet radiation and water (ISO 11507: 1997).

Baines, EF. 2005. A review of the current status of the estimation of emissions from preserved wood and their use in the environmental risk assessment of wood preservatives under the Biocidal Products Directive. Document No. IRG/WP 05-50224-7. International Research Group on Wood Preservation, Stockholm, Sweden

Cui, W.; Kamdem, P.; Rypstra, T. 2004. Diffusse reflectance infrared Fourier transform spectroscopy (DRIFT) and color changes of artificial weathered wood. Wood Fiber Science 36:292301.

Dieguez, M.J. 1994. Lasures, protectors of the wood. Interbimall magazine.Tech. bulletin of AITIM, Spain. pp. 47-51.

Dieguez, M.J. 1997. Finished of wood. Duration to the outside and vitreous transition temperature. AITIM 186. March /April. pp. 60-64.

Feist, W.C.; Hon, D.N.S. 1984. Chemistry of weathering and protection. In: The chemistry of solid wood, R.M. Rowell, ed. Advances in chemistry series 207, Am. Chem. Soc., Washington D.C.USA.

Garay R.; Henríquez, M. 2012. Tratamiento químico de acetilación en madera de Pinus radiata. Maderas-Cienc Tecnol 14(1):103-113.

Garay, R.; Henríquez, M. 2010. Comportamiento al fuego de tableros y madera de pino radiata d. Don con y sin pintura retardante de llama. Maderas-Cienc Tecnol 12(1):11-24.

Garay, R.; Poblete, H.; Karsulovic, J.T. 2009a. Evaluation of oriented strandboard and plywood subjected to severe relative humidity and temperature conditions. Forest Prod J 59(3):84-90.

Garay, R. 2009b. Effect of two Guards Surface Properties Wooden boards, after a year of exposure to the elements. Información Tecnológica 20(4):123-130.

Garay, R. 2009c. Propiedades de tableros estructurales contrachapados y OSB intemperizados durante dos años. Agro-Ciencia 25(1):20-32.

Garay, R.; Ahumada, I. 2008. Comparación de propiedades de suelos laminados. Boletín de Información Técnica 252:26:29. Revista AITIM. España.

Garay, R. 2007. Impregnantes tipo lasur para la protección de la madera y tableros. Agro-Ciencia 23(1):25-36.

Ghosh, M.; Gupta, S.; Kumar, V.S.K. 2015. Studies on the loss of gloss of shellac and polyurethane finishes exposed to UV. Maderas-Cienc Tecnol 17(1):39-44. 
Hikita, Y.; Toyoda, T.; Azuma, M. 2001. Weathering testing of timber-Discoloration. Pages 2732 in Y. Imamura, ed. High-performance utilization of wood for outdoor uses. Press-Net. Kyoto, Japan.

Hon, D.N.S.; Feist, W.C. 1992. Hydroperoxidation in photoirradiated wood surfaces. Wood Fiber Sci 24:448-455.

INN. NCh 819. Of. 2012. Preserved Wood - radiata pine - Classification of service use and risk and sampling. $15 \mathrm{p}$.

Kamdem, D.P.; Grelier, S. 2002. Surface roughness and colour change of copper amine and UV absorbertreated red maple (Acer rubrum) exposed to artificial ultraviolet light. Holzforschung 56:473478.

Lebow, S.; Lebow, P.; Foster, D. 2008. Estimating preservative release from treated wood exposed to precipitation. Wood and Fiber Science 40(4): 562-571.

Lebow, S. 2014. Effect of precipitation pattern on leaching of preservative from treated wood and implications for accelerated testing. Maderas-Cienc Tecnol 16(4):423-434.

LIGNUM. 2014. Wood processing. Higher quality and added value. LIGNUM No 150. pp. 31-33.

Lin, S.Y.; Kringstad, K.P. 1970. Photosensitive groups in lignin and lignin model compounds. Tappi 53:658-663.

Morsing, N.; Lindegaard, B. 2004. Leaching of active components from preservative-treated timber: Stages $2 \&$ 3: Laboratory testing and comparison with semi-field testing. IRG/WP 04-20303. International Research Group on Wood Preservation: Stockholm, Sweden.

Peker, H.; Atılgan, A.; Ulusoy, H.; Goktas, O. 2012. Usage opportunities of the natural dye extracted from acorn (Quercus ithaburensis Decaisne) in the furniture industry upper surface treatment. Int J Phys Sci 7(40):5552-5558.

Tascioglu, C.; Budakci, M.; Yoshimura, T. 2014. Antitermitic effects of three wood stain treatments. Maderas-Cienc Tecnol 16(2):239-244.

Temiz, A.; Yıldız, U.C.; Nilsson, T. 2006. Comparison of copper emission rates from wood treated with different preservatives to the environment. Building and Environment 41(7):910-914.

Temiz, A.; Alfredsen, G.; Yildiz, U.C.; Gezer, E.D. , Kose, K.; Akbas, S.; Yildiz, S. 2014. Leaching and decay resistance of alder and pine wood treated with copper based wood preservatives. Maderas-Cienc Tecnol 16(1):63-76.

Yeniocak, M.; Goktas, O.; Colak, M.; Ozen, E.; Ugurlu, M. 2015 Natural coloration of wood material by red beetroot (Beta vulgaris) and determination color stability under UV exposure. MaderasCienc Tecnol 17(4):711-722.

Williams, R.S. 2005. Weathering of wood. In: Rowell, R.M. (Ed) Handbook of wood chemistry and wood composites. CRC Press, Florida, pp. 139-185. 